\title{
FADS AND FALLACIES IN ASSET LIABILITY MANAGEMENT FOR LIFE INSURANCE
}

\author{
Graham Lord \\ Department of Operations Research and Financial Engineering \\ Princeton University \\ Princeton, NJ 08544, U.S.A.
}

\begin{abstract}
We shall examine the principles behind contemporary approaches to insurance risk management. Furthermore, we shall consider various methodologies, some successful, that have been or are currently employed to implement those principles. We shall illustrate these with several specific studies that show the identification, using simulation, of close-to-optimal investment strategies.
\end{abstract}

\section{INTRODUCTION}

In a very broad sense the management of a complex entity such as an insurance company distills down to the assessment of expectations. From an actuarial point of view this translates into the mathematical quantification of risks and their effects as diverse as mortality, accident, earthquake, weather, economic, and financial. In what follows we shall examine the principles behind contemporary approaches to insurance risk management. Furthermore, we shall consider various methodologies, some successful, that have been or are currently employed to implement those principles. We shall illustrate these with several specific studies that show the identification, using simulation, of close-tooptimal investment strategies.

\section{BASICS OF INSURANCE MATHEMATICS}

There exist few, if any, viable liquid markets in insurance liabilities. Consequently, the two usual approaches in finance for the valuation of generalized contingent cash flows fail. Neither arbitrage arguments nor comparative analyses provide successful means of determining the market value of an insurance product and hence, by aggregation, of an insurance company. Traditional actuarial methods rely on expected utility in which probability weighted projected net cash flows are discounted back to a fixed point in time, $t-$ the valuation date. With the simplest utility function, the identity, this process gives the expected value or, equivalently the (prospective) reserve at time $t$ :

$$
V(t)=\int_{\tau=t}^{\infty} p(\tau ; r) c(\tau ; r) e^{-\int_{s=t}^{\tau} r(s) d s} d \tau
$$

Here, $p$ is the probability a payment of $c$ is made conditioned on the history of the discounting rate, $r$, and the behavioral characteristics inherent in $c$. If these cash flows are those implicit in a particular insurance policy, then the above expected value at the moment the policy becomes in-force the inception of the policy - is its premium before adjustments for commissions, expenses, profit and contingencies.

Note that, embedded in a typical insurance policy are features akin to financial options. In the same policy there may be several option-like riders the company has written to (purchased from) the policy holder.

\section{REALITIES OF VALUATION}

Until recently all insurance policies were essentially priced or valued by the above expected value approach with the simplifying assumptions that (i) the interest rates, i.e., the valuation rates, were constant, (ii) the probabilities are deterministic, and (iii) the cash flow stream, though possibly contingent, is also deterministic. These special conditions, considered to have been reasonable and prudent, have been the default assumptions for actuarial work for decades and in some cases remain so today.

However, competitive pressures in the early 1980s from rival financial institutions, namely retail banks, led insurance companies to develop products that had features more directly competitive with those of the banks. Perhaps the major impact of these innovations was to offer products for which the cash flow was in some way a function of prevailing interest rates and contingent on not only the immediately prior value but on all preceding values. The cash flow, $c$, became interest rate sensitive and path dependent. Examples of these products include Universal Life, Singe Premium Deferred Annuities, Flexible Pre- 
mium Annuities, and Guaranteed Investment Contracts. The traditional actuarial techniques, though reliable for the older policies, were no longer entirely appropriate for valuating the new products.

\section{BEHAVIORAL MODELS}

In life insurance the traditional actuarial assessment of mortality and morbidity risk remains key. However, though these will give robust estimates of the probability of when a payment is made, including the effect of contingent beneficiaries, they fall short in capturing additional policy holder behaviors that affect the evolution of the policy over time. Such additional features would include the partial or full withdrawal of eligible monies in the policy, the borrowing of funds against the policy, the repayment of funds borrowed, the deposit of an additional non-scheduled premium into the policy, etc. Such policy features are offered in order to make a product more attractive to buyers. However, their existence exposes the insurance company to additional risks. By careful product design, risk managers have been able to reduce the effect of some of these risks, though in most cases not completely. We shall examine several attempts to model these supplemental risks.

\section{INTEREST RATE MODELS}

Though it has taken the insurance industry some time to realize the obvious, it is evident that the key to the valuation of interest sensitive insurance products is the modeling of interest rate processes. Consequently, an enormous amount of effort has been expended to develop such models for insurance policy valuation. Christiansen (1982) presents a large - though not comprehensive - list of pre-GARCH-like models. We prefer to employ models originating in financial economics starting with that of Cox, Ingersoll and Ross (1985). We shall discuss several models that have been used in the actuarial domain to effect: Ho and Lee (1986), Jacob, Lord and Tilley (1987), Wilkie (1986), and Mulvey and Thorlacius (1997).

\section{ASSET/LIABILITY MODELS}

The early attempts at integrating insurance assets and liabilities go back to the work of Redington (1952) and Vanderhoof (1972). The foundations of immunization and the use of duration and convexity were essentially laid out in their work. However, it was Boyle $(1977,1978)$ who moved away from deterministic interest rates and resorted to simulation for the cash flow valuation.

In what follows, we consider an example of the stochastic modeling of an insurance product by building on the approach of Boyle (1978), and then Jacob, Lord and Tilley (1987), Tilley (1992) and, more recently, Carriere (2004). We shall look at an asset/liability study that inves- tigates investment strategies for the risk-minimization of an insurance product - a Single Premium Deferred Annuity. We choose the latter, though it is a product with but one premium payment, because its design contains many implicit option-like features, including potentially complex (stochastic) policyholder behavior, in addition to cash flows that are dependent on current and past levels of the term structure of interest rates. To value such features and hence to determine the annuity's "market value" and then to isolate appropriate risk-reducing investment strategies, we lean on a number of simulation methods, including Low Discrepancy sequences. For a general introduction to the latter see Glasserman (2004); refer to Albert, Lord and Vanderhoof (1999) for a discussion on their use in insurance product valuation.

\section{REFERENCES}

Albert, F. S., G. Lord and I. T. Vanderhoof. 1999. Speeding up the valuation process. In Investment Management for Insurers, eds. D. F. Babbel and F. J. Fabozzi, 303-309. New Hope: FJF Associates.

Boyle, P. P. 1977. Options: a Monte Carlo approach. Journal of Financial Economics 4:323-338.

Boyle, P. P. 1978. Immunization under stochastic models of the term structure. Journal of the Institute of Actuaries 105:177-187.

Carriere, J. F. 2004. Martingale valuation of cash flows for insurance and interest models. North American Actuarial Journal 8(3):1-16.

Christiansen, S. L. 1982. A practical guide to interest rate generators for C-3 risk. Transactions of the Society of Actuaries XLIV:101-134.

Cox, J. C., J .E. Ingersoll and S. A. Ross. 1985. A theory of the term structure of interest rates. Econometrica 53:129-151.

Ho, T. S. Y. and S.-B. Lee. 1986. Term structure movements and pricing interest rate contingent claims," Journal of Finance 41:1011-1029.

Glasserman, P. 2004. Monte Carlo Methods in Financial Engineering. New York: Springer-Verlag.

Jacob, D. P., G. Lord and J. A. Tilley. 1987. A generalized framework for pricing contingent cash flows. Financial Management 16(3):5-14.

Mulvey, J. M. and A. E. Thorlacius. 1997. The Towers Perrin global capital market scenario generation system. In World Wide Asset and Liability Modeling, eds. W. T. Ziemba and J. M. Mulvey. Cambridge: Cambridge University Press.

Redington, F. M. 1952. Review of the principles of lifeoffice valuations. Journal of the Institute of Actuaries LXXVII:286-340.

Tilley, J. A. 1992. An actuarial layman's guide to building interest rate generators. Transactions of the Society of Actuaries XLIV:509-538. 
Vanderhoof, I. T. 1972. The interest rate assumption and the maturity structure of the assets of a life insurance. Transactions of the Society of Actuaries XXIV 157:92.

Wilkie, A. D. 1986. A stochastic investment model for actuarial use. Transactions of the Faculty of Actuaries 39(3):341-373.

\section{AUTHOR BIOGRAPHY}

GRAHAM LORD is the president of the investment actuarial company Lord Consulting. He is also a Lecturer at Princeton University where he offers courses in statistics and in Monte Carlo methods for finance and insurance. He received a Ph.D. in analytic number theory from Temple University and a Certificate in Demography from Princeton University. $\mathrm{He}$ is also a Member of the American Academy of Actuaries and an Associate of the Society of Actuaries. Principal current research interests are in Monte Carlo methods and financial modeling. His e-mail address is <glord@princeton.edu $>$. 